\title{
A Situação Hermenêutica e a Clínica Psicológica: Caminhos Possíveis
}

\author{
Angela Cardoso Andrade* \\ Universidade de Fortaleza - Unifor, Fortaleza, CE, Brasil \\ ORCID: https://orcid.org/0000-0001-6845-2861 \\ Carmem Lúcia Brito Tavares Barreto** \\ Universidade Católica de Pernambuco - Unicap, Recife, PE, Brasil \\ ORCID: https://orcid.org/0000-0002-5532-039X
}

\section{RESUMO}

Este estudo tem como proposição discutir os fundamentos de uma clínica psicológica, numa perspectiva fenomenológica hermenêutica, como situação hermenêutica no quadro da MetaOntologia, e segue três momentos. As autoras, ao versarem a clínica como situação hermenêutica com vistas à apreensão e compreensão da facticidade da existência no encontro terapêutico, apontam que seus pressupostos foram delineados inicialmente no Natorp Bericht - Interpretações Fenomenológicas de Aristóteles: indicação da situação hermenêutica. Neste contexto, discutem os três momentos constitutivos fundamentais da situação hermenêutica Blickstand, Blickrichtung e Sichtweite. Em um segundo momento acompanham o avanço desse projeto em Ser e Tempo, em meio à elaboração da Analítica do Dasein e indicam a situação hermenêutica no quadro da Ontologia Fundamental, por outra forma de explicitação - Vorhabe, Vorsicht, Vorgriff. Consideram que a clínica, como situação hermenêutica em sua extensão meta-ontológica, é concebida pela radicalização da Ontologia Fundamental que propulsa a reviravolta da Ontologia, a partir dela mesma. À guisa de conclusão, consideram a possibilidade de uma extensão clínica meta-ontológica da fenomenologia da existência fáctica e ressaltam a questão metódica do ponto de vista meta-ontológico, com realce para o ponto de vista, a perspectiva e o horizonte de sentido, como caminho a ser percorrido na relação clínica.

Palavras-chave: hermenêutica da facticidade, ontologia fundamental, fenomenologia hermenêutica, situação hermenêutica, clínica psicológica.

\section{The Hermeneutic Situation and the Psychological Clinic: Possible Paths}

\begin{abstract}
This study has as proposition to discuss the foundations of psychological clinic, in a hermeneutic phenomenological perspective, as hermeneutic situation within the framework of Meta-ontology, following three moments. The authors, when discussing the clinic as hermeneutic situation, to apprehend and understand the facticity of existence in therapeutic encounter, pointing out the initially outlined assumptions in the Natorp Bericht - Aristotle's Phenomenological Interpretations: indication of the hermeneutic situation. In this context, it
\end{abstract}

ISSN $1808-4281$ 
is discussed three fundamental constitutive moments of hermeneutic situation - Blickstand, Blickrichtung and Sichtweite. The second moment follows the progress of this project in Being and Time, in midst of the elaboration of Dasein's Analytics and points to hermeneutic situation in the framework of Fundamental Ontology, in another explanation - Vorhabe, Vorsicht, Vorgriff. Finally, it is considered that the clinic, as hermeneutic situation in its metaontological extension, is conceived by the radicalization of Fundamental Ontology that propels the turn of Ontology, starting from itself. As guise of conclusion, it is considered the possibility of meta-ontological clinical extension of phenomenology of factual existence and highlights the methodical question from the meta-ontological point of view with emphasis on point of view, perspective and horizon of meaning as way to be travelled in the clinical relationship.

Keywords: hermeneutics of facticity, fundamental ontology, hermeneutic phenomenology, hermeneutic situation, psychological clinic.

\section{La Situación Hermenéutica y la Clínica Psicológica: Posibles Caminos}

\section{RESUMEN}

Este estudio tiene como propuesta discutir fundamentos de una clínica psicológica, en perspectiva fenomenológica hermenéutica, como situación hermenéutica en el marco de metaontología y sigue tres momentos. Primero, cuando las autoras discuten clínica como situación hermenéutica para aprehender y comprender la factibilidad de la existencia en el encuentro terapéutico, señalan que sus suposiciones se esbozaron en el Natorp Bericht de 1922 Interpretaciones fenomenológicas de Aristóteles: indicación de la situación hermenéutica. En este contexto, analiza tres momentos constitutivos fundamentales de la situación hermenéutica - Blickstand, Blickrichtung e Sichtweite. En un segundo momento, siguen el progreso del proyecto en Ser y Tiempo, en medio de la elaboración de Dasein's Analytics y señalan la situación hermenéutica en el marco de la Ontología Fundamental - Vorhabe, Vorsicht, Vorgriff. Finalmente, consideran que la clínica, como situación hermenéutica en su extensión meta-ontológica, está concebida por la radicalización de la ontología fundamental que impulsa el giro de la ontología, por sí misma. Como conclusión, consideran la posibilidad de extensión clínica meta-ontológica de la fenomenología de la existencia fáctica y destaca la cuestión metódica desde el punto de vista meta-ontológico con énfasis en el punto de vista, perspectiva y horizonte de significado como camino a seguir en la relación clínica.

Palabras clave: hermenéutica de la facticidad, ontología fundamental, fenomenología hermenêutica, situación hermenéutica, clínica psicológica.

Uma dimensão a ser destacada como ressonância do pensamento de Heidegger para pensar a clínica psicológica é a reflexão sobre a situação hermenêutica que se faz presente desde o Nartorp Bericht. Tal indicação pode oferecer subsídios para pensar uma clínica psicológica fundada no modo-de-ser desse ente que nós mesmos somos e não a partir de uma 
teoria psicológica regida por premissas teorético-explicativas. Nesta direção, o conhecimento deixa de ser uma função cognitiva e torna-se uma dimensão do próprio ser do homem. A compreensão (Verstehen), enquanto abertura de sentido originária, constitui o homem como ser-no-mundo e, nessa perspectiva, o conhecimento se funda na elaboração do que já se abriu de maneira não temática, elaboração explicitada na interpretação.

Partindo de tal pressuposto, o presente estudo tem como proposição central apresentar a prática psicológica clínica como situação hermenêutica em sua extensão meta-ontológica. Para tanto, será apresentado o caminho percorrido pelo jovem Heidegger na elaboração da fenomenologia como hermenêutica da facticidade no Natorp Bericht ou Informe Natorp. Em seguida, será demonstrado como estes pressupostos são evidenciados na Ontologia Fundamental e caminham em sua radicalização numa ôntica-metafísica ou extensão ontológica no plano ôntico (Sá, 2008). Seguindo por esse caminho, no terceiro momento, as autoras indicam a possibilidade da prática clínica inscrita no plano ôntico ser fundamentada pela hermenêutica da vida fáctica, tal qual elaborada no projeto inicial de Heidegger e avança em complexidade em Ser e Tempo de 1927 e nas preleções ministradas no verão de 1928. A Meta-Ontologia apreendida no projeto heideggeriano surge como proposta de explicitação dos pressupostos ontológicos tematizados na Analítica do Dasein em sua correspondente apreensão do ôntico.

\section{O Alvorecer da Situação Hermenêutica em Heidegger - Natorp Bericht}

O conteúdo real de toda interpretação, quer dizer, o objeto temático na maneira em que foi interpretado, só chega a se mostrar direta e adequadamente, quando a correspondente situação hermenêutica da qual depende toda interpretação resulte acessível de uma maneira suficientemente clara (Heidegger, 2002, p. 29, tradução nossa).

Os primórdios do pensamento do jovem Heidegger, que segue com autonomia ao ministrar suas primeiras preleções na Universidade de Freiburg, ano seguinte ao pós-guerra, em 1919, contrapõem-se à filosofia como ciência de rigor com a sua proposta de filosofia como concepção de mundo, sob os títulos: Para uma definição da filosofia; A ideia de filosofia e o problema de concepção de mundo. A originalidade de seu pensamento, no início de sua cátedra, gira em torno da significação da palavra vida, presente na pergunta que guia o 
seu pensamento: o sentido da vida humana. Essa, junto à compreensão prévia do ser, direciona a produção do jovem Heidegger.

Assim, na busca de acessar a realidade primeira da vida, Heidegger segue um caminho que se inicia com a desconstrução da história da metafísica e continua com a transformação hermenêutica da fenomenologia de Husserl. Deste modo, descerra que a única forma de acesso aos fenômenos vitais, como experiências originárias e, portanto, fundamentais, é a rejeição à teoria representacional da vida e ao uso categorial da linguagem. Adverte a necessidade de destruição ${ }^{1}$ (Destruktion) fenomenológica da história, ou seja, como análise e esclarecimento dos fatos e conteúdos de uma época em termos científicos, e defende a assunção da dimensão significativa da vida fáctico-histórica (Heidegger, 2011). Heidegger menciona que, desde Platão e Aristóteles, a tradição filosófica lidou com uma compreensão mediana de ser de tal modo que a temporalidade do ser era meramente dada e, com vistas a essa máxima, a destruição dos conceitos da tradição se afirma num processo crítico de desmonte - confronto e reapropriação - das fontes nas quais tracejou o edifício do pensamento ocidental. Assim, e somente por esta forma, a ontologia se asseguraria do caminho fenomenológico de apreensão de seus conceitos originais, tornando-se, portanto, genuinamente fundamental (Heidegger, 2012a). Heidegger deixa claro que a construção fenomenológica implica essencialmente uma destruição, no sentido de uma desconstrução, indicando um mútuo-pertencimento entre construção e destruição no ver fenomenológico. Não se trata, porém, de uma negação dos conceitos ontológicos tradicionais e, sim, de propor novos fundamentos de tal maneira que possibilitaria uma assimilação das possibilidades mais próprias da tradição.

Tendo isso em vista, Rubenich $(2014$, p. 22) alude que "Assim, não se trata de esclarecer a objetividade do histórico em termos científico-teóricos, mas, antes disso - e, portanto, primordialmente -, trata-se de abordar a questão radical do sentido do ser histórico". Desta maneira, Heidegger busca fundar a Fenomenologia Hermenêutica como ciência originária $^{2}$ que supera o domínio teorético e explicativo da vida com as suas inseparáveis qualidades abstratas, que obscurecem o sujeito histórico em seu plexo de significatividade. A partir dessas (des)construções, sobretudo a atenção dada por Heidegger à fenomenologia de Husserl, tendo como referência a hermenêutica diltheyniana, abre-se o esteio pelo qual a hermenêutica pela primeira vez na filosofia assume a significação filosófica ontológica fundamental (Gadamer, 2007). Neste panorama de destruição (Destruktion) da metafísica, por entender a filosofia como investigação radical-histórica, a construção da hermenêutica da 
facticidade iniciou o percurso que conduziu Heidegger a Ser e Tempo, em 1927 (Heidegger, 2009).

Seguindo o pensamento heideggeriano como menção, a facticidade ou vida fáctica é a proposta radical e originária de interpretação fenomenológica do Dasein humano, por não ter caráter de objeto, mas tão somente de significatividade. A Hermenêutica da Facticidade, portanto, é fruto de amplas elaborações em torno do significado da palavra vida a qual se torna o modo de acesso à questão do ser (Rubenich, 2014). No entanto, à época do início de sua cátedra, o Dasein era muito recorrentemente mencionado por Heidegger como o ente na totalidade, no qual indica que este ente pode falar por si mesmo, mostrando-se como fenômeno, para além de toda e qualquer aplicação a priori de aportes teóricos e categorias analíticas. Com isso, o alvitre investigado por Heidegger seria a “(...) fundação de uma ciência rigorosa da vida. Assim, sua Hermenêutica Fenomenológica da facticidade não seria nem concepção e nem teoria (...) [seria] como prolongação de um movimento fundamental [Grundbewegheit] que se encontra na mesma vida fáctica" (Peraita \& Santos, 2009, p. 77).

Para Hebeche (2003), em seu escrutínio pela fase do jovem Heidegger, o filosofar para o mestre não coincidia mais com a Filosofia e seu quadro conceitual de imagens advindas do pensar objetivante, de tal modo que "a metafísica grega e a antropologia cristã passam a ser consideradas modos de encobrimento da vida fáctica" (p. 1315). Deste modo, afirma que, no cerne das preleções iniciais, o filosofar deveria radicalizar a interpretação dos textos clássicos com a destruição da história da metafísica na busca de elaborar uma interpretação ontológicofenomenológica do problema fundamental da vida fáctica. Assim, a facticidade reabilitaria o fundo sobre o qual foi edificado todo o pensar filosófico.

O Informe Natorp ou Natorp Bericht de 1922 - Interpretações Fenomenológicas de Aristóteles: indicação da situação hermenêutica, obra que precede a Ser e Tempo de Martin Heidegger, fornece as interconexões necessárias entre a ontologia, a fenomenologia e a hermenêutica, nas quais são analisados e elaborados, em torno da questão da facticidade ou da vida fáctica, conceitos provenientes de Dilthey que significam existência concreta, histórica (Heidegger, 2010). Diante destes pressupostos, integram-se a apropriação e interpretação por Heidegger da noção de práxis do livro VI da Ética a Nicômaco, o terceiro livro do De anima, os livros I, VII e XIX da Metafísica e o primeiro livro da Física, entre outras menções do pensamento aristotélico (Volpi, 2013). Assim, propõe que a vida fáctica, conforme sua dimensão ontológica, deve ser compreendida como vida histórica, a partir de modalizações próprias e envolta pela temporalização concreta de seu ser. Deste modo, o sentido do ser passa pela tematização das estruturas constitutivas do único ente que compreende o sentido de 
ser. Ente este compreendido como vida humana - Dasein. A primazia do sujeito epistemológico e a teoria do conhecimento atemporal e ahistórico são abandonadas em favor dos contextos práticos de ação da vida fáctica que ressaltam as dimensões histórica e simbólica da vida humana (Peraita, 2002).

Nesse horizonte da compreensão do ser do ente, a problematização heideggeriana acena para a questão da situação hermenêutica, que tende a mostrar a vida em si mesma; em sua própria mobilidade (Bewegtheit) enquanto vida fáctica. Por este entendimento, Heidegger disserta que a ontologia como ciência do ser dos entes só é possível como fenomenologia (Heidegger, 2012b). No entanto, a fenomenologia descrita como um esforço de investigação, na qual possibilita a manifestação das coisas em seu sentido, somente se concretiza como hermenêutica do Dasein. Esta transformação hermenêutica da fenomenologia se afasta e substitui a filosofia da consciência baseada na percepção proposta por Husserl e ressalta a compreensão como estrutura na qual o ser é compreendido. Heidegger, ao propor a compreensão como condição estrutural do ser do homem, desloca a fenomenologia e a hermenêutica para o plano ontológico. A ênfase recai, portanto, na interpretação como modo de acesso ou condição de possibilidade da manifestação do sentido do ser, ao assumir a tarefa primordial de tornar visível o como da vida fáctica que não pode ser apreendido teoreticamente ou de forma representacional, tendendo a se tornar universal, mas somente pela descrição fenomenológica ou indicação da situação-hermenêutica. Noutras palavras, uma "forma de apreensão fenomenológica do ser na vida fáctica" (Wu, 2012, p. 562). A interpretação proposta por Heidegger não visa a compreensão final e entendimento de algum tipo de objeto como a proposta da hermenêutica clássica, mas acena para a compreensão da movimentação própria da vida, tal qual ela se apresenta por si essencial, tornando visível o fenômeno da existência humana, do ser deste ente, que é a maneira do Dasein. Desta forma, "é preciso assumir que a interpretação está sempre relacionada com a tarefa fenomenológica de tornar o ser do fenômeno visível por si mesmo" (Wu, 2012, p. 563).

Heidegger (2012b), em texto que compila suas preleções ministradas no verão de 1923 na Universidade de Freiburg, busca compreender e tematizar a facticidade como um termo que tem por desígnio o caráter próprio do Dasein, não como coisa ou objeto, mas em sua cotidianidade na qual já sempre é ou está aí, demonstrando que esse ente já se encontra originariamente aberto ao ser.

Por conseguinte, por fáctico chama-se algo que é articulando-se por si mesmo sobre um caráter ontológico, o qual é desse modo. Caso se tome a vida como um modo de 
ser, então, vida fáctica quer dizer: nosso próprio ser-aí enquanto aí em qualquer expressão aberta no tocante a seu ser em seu caráter ontológico (Heidegger, 2012b, p. 13).

Para que tal atividade se torne possível, Heidegger aponta indicativos formais ${ }^{3}$ os quais se configuram em um campo que propicia não somente uma exigência metódica, mas as condições necessárias para que a interpretação e compreensão do modo de ser do ser humano 4 - Dasein - sejam apreendidas enquanto mobilidade da vida fáctica em sua vitalidade imediata. Importa ressaltar que o formal é compreendido como ponto de partida de uma mostração não definitória e apenas sugere, assinala a pista dos fenômenos vitais. Já que a fenomenologia hermenêutica não tem um objeto designado, a expressão formal-indicativa é encontrada no acontecimento da própria vida fáctica. Nesta direção, "compreender o conteúdo de um conceito fenomenológico, realizando-o, quer dizer, simplesmente, vivê-lo!" (Sena, 2012, p. 46).

Feitas tais considerações, que possibilitam compreender o fio condutor do pensamento do jovem Heidegger, agora importa uma aproximação ao Natorp Bericht ou Informe Natorp (Heidegger, 1922/2002) já que apresenta as condições necessárias do interpretar e do compreender, focalizando as interpretações, a partir da subordinação aos três momentos constitutivos fundamentais, nos quais qualquer atividade de compreensão e interpretação ocorre. Heidegger anuncia, nessa obra, o que faria mais tarde em Ser e Tempo, em 1927, no que se refere aos marcos correlacionais entre ontologia, fenomenologia e hermenêutica, a partir da existência fáctica e temporalidade. Heidegger adverte, neste Informe, que a existência não deve ser interrogada de uma maneira genérica e direta, de tal modo que a mostração da existência só se torna compreensível, a partir da construção/destruição do que originariamente se mostra acerca dos motivos de suas ações, orientações e disposições voluntárias. A aparição do ser em sua facticidade concreta, ou seja, em seu projeto de vir-aser histórico, é o modo pelo qual há a possibilidade de evitar interpretações consagradas no âmbito científico de evidência absoluta e sistemática que mantém o ser em seu velamento. Por esses interstícios, a vida fáctica tende a não se mostrar ou evitar o encontro consigo mesma, já que o ser-aí mesmo não é acessível ao olhar objetificante, tendendo ao encobrimento (Heidegger, 2010). A vida fáctica, por se mostrar em constante movimento de gestação histórica, indica para a necessidade de desconstrução dos diversos paradigmas hermenêuticos que mascaram o genuíno fenômeno da vida. Daí a necessidade de uma ciência originária, simultânea à desconstrução da tradição metafísica, que possibilite a apreensão da experiência 
fáctica da vida, já que a existência só se torna compreensível em seu próprio ser no momento em que se interroga a facticidade.

Diante de tal compreensão, a hermenêutica da facticidade se apresenta como possibilidade de apreensão da abertura originária de sentido na qual se encontra o Dasein enquanto ser-no-mundo. Assim, o como de cada objeto temático no cerne de seu ser somente poderá se constituir propriamente se a correspondente situação hermenêutica for explicitada com suficiente clareza. O objetivo primordial é encontrar o acesso através do qual a direção de visada do intérprete ou pesquisador possa apreender o ser da vida fáctica em seu horizonte de sentido (Heidegger, 1922/1989). Dito de outra forma, a investigação torna-se uma apropriação da mobilidade em termos do ser do Dasein humano, que desde sempre já é précompreensão. Entretanto, "se alguém quer alcançar o fenômeno da vida fáctica, ele precisa começar a investigação, a partir da própria situação concreta, e não a partir de um ponto de vista exterior" (Wu, 2012, p. 564). Logo, em sua forma de indicação, essa possibilidade de investigação assume um movimento dinâmico e circular, evidenciando a implicação indubitável da situação hermenêutica do intérprete, na mostração do fenômeno.

Rubenich (2014) faz referência ao giro hermenêutico na experiência da vida fáctica e à noção de temporalidade na preleção de Heidegger em 1921- Introdução à fenomenologia da religião -, anterior ao Natorp Bericht de 1922, mas que se inscreve no relatório Natorp como Hermenêutica da Facticidade no sentido de indicar o caminho metódico em que a situação hermenêutica mostra a existência em seu caráter temporal no ser da vida fáctica de maneira realizadora. Desde sempre presentes nas elaborações do jovem Heidegger, Rubenich lembra que a apreensão de sentido da problemática posta em jogo no desvelar fenomenológico e suas conexões fundantes encontram ascendência originária na vida fáctica, cuja mobilidade própria emerge numa dinâmica temporal que designa os existenciários, ou formalmente indicados por Heidegger como categorias. Enfatiza, entretanto, que por insurgir numa dinâmica viva de forma realizadora, tais categorias não são ordenadoras e reguladoras. São hermenêuticas, portanto, o Dasein, em sua constituição ontológica fundamental e ao se realizar como abertura historicamente dada, é temporalidade. Daí ser possível indicar que "Isso significa que o sentido do ser deve ser conquistado a partir do sentido do ser que é história, ou seja, do próprio ser-aí, pensado como ente exemplar que compreende ser" (Rubenich, 2014, p. 23).

No jogo fenomenológico radical, a questão metódica, na qual explicita os modos concretos da experiência fundamental, faz menção à pergunta como o ser se dá? em detrimento da pergunta o que é o ser? O como institui a dependência originária do encontro do Dasein consigo mesmo e para ser-com-os-outros e, por conseguinte, destina a forma pela qual 
o ser-aí pode estar desperto; acorda para a tarefa principal do pensamento, o desencobrimento do ser (Heidegger, 2012b).

A situação hermenêutica tem como mote de partida um ponto de vista fixo e próprio Blickstand - mais ou menos explícito, que indica a posição inicial de visada implicada no problema da facticidade. Tem como entendimento a assimilação dos referenciais que nos constituem e passam a fazer parte do patrimônio de experiências e vivências da pessoa, sedimentando-se num solo existencial pré-compreendido originariamente. Heidegger (1922/2002) descreve como sendo uma plataforma que posiciona a pessoa no jogo interpretativo. Mesmo não sendo plenamente consciente, a forma como julgamos e interpretamos diz respeito ao modo a partir do qual somos e nos posicionamos. A partir desta primeira coordenada também são definidas as atitudes fundamentais em relação à história enquanto horizonte prévio e a orientação do olhar. Pela dinâmica plenamente interativa e circular da situação hermenêutica, o passado é apreendido numa perspectiva do tendo sido, ou seja, de forma realizadora. A dinâmica temporal ek-stática - existência enquanto projeto e lançada - dimensiona o passado num presente vivo. Desta forma, a apropriação compreensiva do passado é o presente vivo; o passado não passou, é sido no meu estar presente. Ou no dizer de Rubenich (2014, p. 23), "a experiência da vida fáctica pode se mostrar em sua historicidade. (...) O histórico tem seu sentido haurido da vida, ela mesma como ocorrência no tempo, como surgir e se tornar".

A partir dessa posição inicial de visada, na qual transparecem os pré-conceitos sedimentados, verte-se o segundo momento - Blickrichtung - como sendo a perspectiva de apreensão do ser do objeto captado e a direção do olhar que move a interpretação. Nesse âmbito, é determinado como o quê, ou seja, o modo como o objeto da interpretação deve ser conduzido de maneira pré-conceitual e em direção ao que deve ser interpretado. O conteúdo de cada interpretação, ou seja, o como do ser do objeto temático ou a temática problematizada, deverá estar plenamente clara no jogo da circularidade fenomenológicointerpretativa. Por essa dinâmica, não há coisas em si, mas o modo pelo qual ou a maneira que tal coisa é compreendida. Cada interpretação, portanto, é relativa em suas características singulares, na medida em que ao se apropriar de uma compreensão, a interpretação se move, compreendendo, na direção de uma totalidade conjuntural já compreendida. Assim, a interpretação é a realização do compreender.

O terceiro momento - Sichtweite - é a amplitude de visão; delimitado pelo horizonte no qual se move a interpretação. É a última coordenada da interpretação, na qual é delimitada pelo ponto de vista e pela orientação do olhar. Deste último, o objeto temático da investigação 
deve ser esclarecido e dentro dele se move a pretensão correspondente de objetividade da interpretação. Por outras palavras, o processo de apropriação crescente do objeto temático da interpretação e compreensão projeta sentidos, difunde a esteira existencial de possibilidades enquanto horizonte epocal, cuja moldura emerge como exigência de objetividade na qual a interpretação se move. A mobilidade alcançada pela situação hermenêutica em sua radical transparência tem que ser capaz de descrever os dados da situação e pôr em relação com a situação base, com o ponto de vista ou mirada inicial de visada. Por essa assertiva, temos que, em qualquer que seja o âmbito temático no qual se move a interpretação, a exigência de objetividade se constitui como marco sustentador da situação hermenêutica, na qual deverá estar desperta, ou de forma plenamente transparente, a temática investigada e a transitividade pelas três dimensões do interpretar e compreender.

Peraita (2002) reflete em torno do Informe Natorp e problematiza sobre as três condições que movimentam a situação hermenêutica em seu caráter de objetividade. Destaca o esforço de Heidegger na busca da apreensão dos conceitos prévios e o direcionamento do olhar do intérprete que torna possível as compreensões nas quais movem a interpretação, a fim de tornar transparente, para além da herança conceitual sedimentada, a vida em seu horizonte originário. Heidegger (2010), portanto, no Informe Natorp, tem como proposta explicitar as condições do interpretar e compreender, que possibilitam a apropriação e interpretação da temática investigada. A situação hermenêutica é impelida pelo movimento interpretativo no qual a vida é encontrada, tanto no presente, como no passado vivo - no tem sido, quanto no porvir - o ainda não do já. Por essa questão, o que torna imprescindível na investigação é a clarificação do objeto temático no âmbito pré-teórico e não objetivo que a vida tem em si mesma em sua facticidade, ou seja, na mostração própria das categorias existenciais ou existenciários que se expressam e se referem em modulações ek-státicas. Para Heidegger, então, o sentido da filosofia é a realização do dinamismo fundamental da vida fáctica; torna-se um aspecto da vida, pensando nela própria de tal modo que a vida realiza a filosofia num incessante continuиm de desdobramentos de sentidos no mundo, demarcando o que mais adiante tornar-se-á o ser-aí humano - o Dasein - pela correlação originária de poderser e, assim, correspondendo à indeterminação ontológica original que, incontestavelmente, lança o ser do existente humano como abertura projetiva ao ser, um projeto que desde sempre é compreensão de ser-no-mundo, com isso inconclusivo.

Ainda importa ressaltar que o mundo, para a fenomenologia heideggeriana, que já assume contornos próprios em suas preleções iniciais em Freiburg, refere-se a um campo existencial globalizante de manifestação dos entes, porquanto para a fenomenologia não 
existe a realidade em si, mas realidade percebida como. Deste modo, a intencionalidade no Informe Natorp, entendida por Peraita (2002), é apresentada de forma vinculada à ideia de situação hermenêutica e facticidade. A autora discorre que, para Heidegger, as relações intencionais (Intentio - que significa direcionar-se para; movimento para fora de si que correlaciona e liga, forma de noema e, Intentum - que expressa o correlato de pertença recíproca, forma de noésis) são atos que subjazem e conjugam as experiências vividas. Por esse alvitre, a intencionalidade é compreendida como comportamento (Verhalten) no sentido de comporta-se e de referência que indica, portanto, relação. Desta maneira, a relação assumida no informe é mais originária e é descrita como Intentionalitäto bjetiviert “intencionalidade objetivada" (Peraita, 2002, p. 44). Por estes esclarecimentos, o objeto temático nunca é entendido em seu conteúdo material e objetivo, mas concebido apropriadamente como Verhalten. O objeto é o que é quando comparece como fenômeno, por outras palavras: "O para o quê e o respeito do que da referência" é o delineamento do objeto para Heidegger (Peraita, 2002, p. 46). No entanto, ainda afirma que, para que o objeto se apresente em sua plenitude, a objetividade tem que ser fixada interpretativamente em pleno sentido existencial, o que significa que é o mesmo de ser abordado hermeneuticamente. Somente dessa forma, o objeto comparece como fenômeno quando se toma em consideração a correspondente situação hermenêutica.

Por estas proposições tecidas no Informe Natorp, resgataremos adiante essas elucidações na compreensão da prática psicológica clínica como extensão meta-ontológica em sua radicalização da Analítica do Dasein explicitadas pela Ontologia Fundamental.

\section{A Situação Hermenêutica na Perspectiva da Ontologia Fundamental}

Interpretar não é tomar conhecimento do que se compreendeu, mas elaborar as possibilidades projetadas no compreender (Heidegger, 2015, p. 209).

A situação hermenêutica, como apresentada no Natorp Bericht, discutida no item anterior, possibilita, no período da Ontologia Fundamental desenvolvida em Ser e Tempo, pensá-la como circularidade hermenêutica: compreensão, interpretação e sedimentação. Esta, por sua vez, abre a possibilidade de vislumbrar o quadro meta-ontológico, que apresenta uma compreensão da situação hermenêutica fundada na radicalização da Ontologia Fundamental.

Antes de adentrar para discutir a possibilidade de uma compreensão meta-ontológica da clínica psicológica, importa resgatar algumas compreensões tecidas na Ontologia 
Fundamental de Heidegger, em Ser e Tempo, as quais vão subsidiar as reflexões que serão encaminhadas. Importa ressaltar que no $\S 8$ de Ser e Tempo, Heidegger (2015) já lança alguns indícios sobre a possibilidade de análise da dimensão ôntica da existência humana, ou seja, em sua realização concreta e histórica no mundo. Argumenta que, apesar da questão sobre o sentido de ser seja a mais "universal e vazia" (p. 79), ela resguarda sempre a possibilidade de singularidade em cada Dasein. Nesta direção, há a necessidade de um fio condutor para atingir a conceituação exigida e fundamental de "ser" que se dá seguindo a interpretação de um ente determinado - o Dasein (Heidegger, 2015, p. 79).

Em Ser e Tempo, Heidegger (2015), no § 32, avança em seu projeto fenomenológicohermenêutico, traçado inicialmente no Natorp Bericht (Heidegger, 1922/2002), como extensão da elaboração da Analítica do Dasein em seus fundamentos ontológicos como compreensão e interpretação. A continuidade da problemática traçada acerca da Hermenêutica da Facticidade na Ontologia Fundamental orienta a apreensão do Dasein em sua realização, sendo desde sempre compreensão de tal modo que projeta o seu ser em possibilidades enquanto abertura numa dinâmica ek-stática articulada em sentido. A proposição central que assume a hermenêutica como interpretação na Ontologia Fundamental insurge sobre a questão da compreensão que se desenvolve de modo circular, ou seja, com a apropriação crescente do objeto temático no círculo hermenêutico. Neste fio condutor, a interpretação é a realização mesma do compreender que, a partir da apropriação do compreendido, se modaliza incessantemente em precípuas interpretações. Desta maneira, portanto, a interpretação não é diferente da compreensão, é a própria realização da compreensão. "Na interpretação, o compreender vem a ser ele mesmo e não outra coisa. A interpretação funda-se existencialmente no compreender e não vice-versa" (Heidegger, 2015, p. 209). Para tanto, Heidegger indica as condições essenciais para essa tarefa do interpretar e do compreender atinentes à hermenêutica, mas com outra forma terminológica na Analítica do Dasein em Ser e Tempo. Heidegger irá mostrar quais são os princípios da hermenêutica como uma dinâmica circular que se inicia pela pré-compreensão e que se aprofunda, ampliando interpretativamente essa compreensão, com base numa sedimentação epocal na qual irá haurir o sentido próprio de pertença de nossas circunstâncias concretas e históricas. A dinâmica hermenêutica acerca-se de três momentos constitutivos: O ter prévio ou propósito (Vorhabe), o ver ou visão prévia (Vorsicht) e a concepção ou captar prévio (Vorgriff).

O ter prévio - Vorhabe - parte de uma totalidade conjuntural já compreendida, cujo propósito como ter prévio funda-se no ponto de partida no qual a compreensão ainda velada irá mover a interpretação na direção de uma totalidade conjuntural já compreendida. Neste 
movimento, o desvelamento é orientado pelo ponto de partida que fixa o parâmetro daquilo que deve ser interpretado. O ver prévio (Vorsicht), em sua forma própria de cuidado, é ter cautela com, recorta o que é apreendido no ter prévio no qual "o compreendido há de ser interpretado, (...) torna-se conceito da interpretação" (Heidegger, 2015, p. 211). Seja de qual modo se movimenta a interpretação, a dinâmica hermenêutica sempre se move numa determinada forma de concepção na qual se funda numa captação prévia ou pré-conceito (Vorgriff). A compreensão de algo como algo é sempre fundada pelo ter prévio do propósito, pelo ver prévio cauteloso e pela apreensão prévia, enquanto pré-conceito. Daí se pode concluir que a interpretação sempre supõe pressupostos que podem direcionar uma determinada apreensão do fenômeno (pré-conceito) que se deseja compreender.

A situação hermenêutica no quadro da Ontologia Fundamental permite aprofundar essas noções e, portanto, compreender melhor a caminhada circular da interpretação e da compreensão. A interpretação, ela própria, é uma forma de desconstrução, na medida em que o compreender se apropria, compreendendo, do compreendido, o que significa dizer que interpretar conforme a nossa própria situação hermenêutica é encontrar sempre novas compreensões num presente vivo. Para a hermenêutica, o passado não é compreendido como um saber superado com um caráter explicativo que determina o presente. É considerado como algo fundamental e a descrição fenomenológica não se apresenta de forma abstrata que visa o que da vida - objeto da investigação metafísica sobre o ser. Assim, é possível indicar que o projeto estruturado pelo ter prévio, pelo ver prévio e pela captação prévia aponta para a dimensão do sentido, a partir do qual algo é compreendido como tal algo. Compreensão pautada no como da vida fáctica na busca de apreender o fenômeno que é em si na sua mobilidade. Ser mobilidade, no Relatório Natorp, implica que as diversas direções do cuidado estão voltadas para o mundo em torno, ainda não há menção ao cuidado como preocupação (Fürsoge). Em Ser e Tempo, o cuidado como o ser do Dasein evidencia uma interpretação ontológico-existencial e exclui qualquer possibilidade da significação ôntica, como cuidado e descuido. Refere-se, desta forma, como modos de cuidado no sentido existencial.

Nessa direção, as determinações primordiais que estruturam o ser do Dasein como dinâmica ek-stática - disposição afetiva, compreensão e linguagem - explicitam que o ser-aí em sua determinação ontológica fundamental como compreensão é desde sempre lançado num conjunto de significados historicamente sedimentados (Heidegger, 2015). Esta compreensão prévia é captada no âmbito da abertura tonal ou disposição afetiva, que se articula pela fala, pela linguagem, ao interpretar o modo como o ser-aí se ocupa no mundo 
segundo os envios próprios de seu horizonte epocal. Desta forma, o Dasein é "compreensão como sempre enraizada numa determinada situação" (Sá, 2008, p. 9).

Pelo continuum da obra heideggeriana, encontra-se a maneira que Heidegger conduz a Hermenêutica da Facticidade no projeto da Ontologia Fundamental e, por conseguinte, avança nas Preleções do Semestre do Verão de 1928, ao indicar o caminho meta-ontológico no qual os princípios da Analítica Existencial são apreciados numa perspectiva ôntica, aqui representada pela clínica psicológica. Por este caminho, é possível elaborar a moldura pela qual o exercício da prática psicológica clínica, do caso em particular, pode ser orientado em seus fundamentos pela explicitação dos indicativos formais da ontologia fenomenológica como realidade da existência - meta-ontologia, cujo método próprio construtivo/destrutivo tem como proposta alcançar a dinâmica circular do existir, ou seja, a apreensão do sentido que se produz ao existir.

\section{A Clínica Psicológica como Situação Hermenêutica: Caminhos pela Perspectiva Meta- ontológica}

A situação hermenêutica no quadro da Meta-Ontologia propulsionada pela reviravolta da Ontologia, a partir dela mesma, permite trazer à explicitação a tendência implícita à própria ontologia: a sua tradução numa mera ôntica. A partir de tal compreensão, BorgesDuarte (2016) aponta para a possibilidade de uma aplicação ôntica da meta-ontologia, enquanto exercício do cuidado, para a explicitação de uma situação clínica psicológica da existência fáctica. Tal caminhar culmina na possibilidade de uma situação hermenêutica no quadro da Meta-Ontologia, que abre para a possibilidade de uma extensão clínica metaontológica da fenomenologia da existência fáctica, que se apresenta com base e para além da Ontologia Fundamental.

Paralelamente, para Sá (2008), a incompletude do projeto inicial de Ser e Tempo implica uma insuficiência da análise do Dasein do ponto de vista ôntico. Tal análise só poderia ser satisfatoriamente explicitada em abordagens ônticas, "mas já ontologicamente fundadas, da sua região ôntica particular" (Sá, 2008, p. 34). Ressalta que a análise do Dasein, empreendida em Ser e Tempo, apresenta uma análise apenas ontológica e não ônticamente suficiente. Ao considerar tal contexto, Sá aponta para a possibilidade de tentar reconstruir uma análise do Dasein que contemplasse a dimensão ôntica, possibilidade abandonada por Heidegger em 1928, quando se afasta da análise que designa como ôntica metafísica ou metaontológica. Importa ressaltar que a constituição ontológica do Dasein implica uma dimensão 
ôntica enquanto determinante do ente, que é Dasein. Daí, apesar de a análise publicada em Ser e Tempo poder ser considerada insuficiente para a dimensão ôntica do Dasein, ela é necessária e vinculante para a elaboração da Ontologia Fundamental. A investigação empreendida em 1929, na volta de Heidegger a Freiburg, inicia uma sistematização de uma Metafísica do Dasein. Tal investigação tem como objetivo a duplicidade ôntico-ontológica do Dasein enquanto ser humano que vai ser desenvolvida, posteriormente, por Medard Boss, especialmente nos Seminários de Zollikon (1959-1969). Em tal situação, Heidegger aceita o desafio que a Ontologia Fundamental e sua evolução para a História do Ser possa se apresentar como orientação para uma prática clínica - Daseinsanalyse (Borges-Duarte, 2016).

Por esse correlativo entendimento, Sá (2008), ao percorrer o continuum do método fenomenológico, em seus momentos interconexos de construção/confrontação phänomenologische Konstruktion/phänomenologische Destruktion -, indica na obra heideggeriana os acessos ao pensamento em que há a tematização explícita por Heidegger acerca de uma apreciação meta-ontológica do Dasein e a indicação decisiva de uma análise que possibilita a apreensão e compreensão no plano ôntico, a partir dos princípios da Ontologia Fenomenológica, como extensão meta-ontológica, permitindo, por conseguinte, as argumentações de dimensões éticas, inclusive.

Seguindo tais considerações e ousando ir adiante, é possível indicar a possibilidade de uma extensão clínica meta-ontológica da fenomenologia da vida fáctica (situação concreta trabalhada na clínica psicológica) a qual pode ser descrita como uma clínica do cuidado ou da solicitude, compreendida como ser-com, que acontece no encontro e no diálogo entre terapeuta e paciente. Tal compreensão delineia um horizonte meta-ontológico da terapia, que tem como proposta a reapropriação da existência, que pode ser compreendida como cura, no sentido radical.

Isso posto, e considerando as preleções do semestre do verão de 1928 por Heidegger, e refletidas por Sá (2008), é possível elaborar os caminhos pelos quais o exercício da prática psicológica clínica, enquanto uma investigação do ôntico, do caso em particular, pode ser orientado em seus fundamentos pela explicitação dos indicativos formais da ontologia fenomenológica como realidade da existência, cujo método próprio construtivo/destrutivo tem como proposta alcançar a dinâmica circular do existir, ou seja, a apreensão do sentido que se produz ao existir. Assim, as três determinações primordiais que estruturam o ser do Dasein como dinâmica $e k$-stática - disposição afetiva, compreensão e linguagem - explicitam que o ser-aí em sua determinação ontológica fundamental como compreensão é desde sempre lançado num conjunto de significados historicamente sedimentados (Heidegger, 2015). Esta 
compreensão prévia é captada no âmbito da abertura tonal ou disposição afetiva, que se articula pela fala, pela linguagem, ao interpretar o modo como o ser-aí se ocupa no mundo segundo os envios próprios de seu horizonte epocal. Desta forma, o Dasein é "compreensão como sempre enraizada numa determinada situação" (Sá, 2008, p. 9).

Heidegger (2017), nos Seminários de Zollikon, ao se referir à relação clínica entre analista e paciente, sobre o interesse mútuo existencial que existe nessa relação, designa que pela Daseinsanalytica, o "Dasein é um ente em que, sendo, está em jogo seu próprio ser. (...) É como o nome indica, uma interpretação ontológica determinada do ser-homem como Dasein" (p. 139). Isto somente indica a vivência do existenciário ser-com como um horizonte de manifestação do Dasein no mundo. Desta forma, essa relação clínica pode ser "vivida como uma relação de Dasein para Dasein" (Heidegger, 2017, p. 139). Considera que a ambiência clínica dialógica da Daseinsanalyse se insere no âmbito ôntico em que favorece interrogar, como exemplo, desde o como se dá o "ser-uns-com-os-outros" (Heidegger, 2017, p. 139) até mesmo a análise dos sonhos do paciente. A práxis clínica, em sua dinamicidade dialógica, é a consumação da exposição dos caracteres ontológicos do ser-aí, ou seja, é o executar dos existenciais que constituem a Analítica do Dasein em sua cotidianidade, não assumindo, portanto, nenhuma forma teórico-categorial. Afirma Heidegger (2017), que a situação clínica é o campo de descrição e mostração fenomenal de cada caso, de cada Dasein factualmente existente. Nesse mesmo seminário, em Zollikon, de 23 de novembro de 1965, Heidegger explicita, contundentemente, que cada fenômeno que surge na relação entre paciente e terapeuta deve ser orientado enquanto conteúdo fenomenal em sua pertinência ao paciente em si, em sua historicidade concreta, não subsistindo a essa investigação metódica a mera classificação dos fenômenos, mas ser orientada pelas indicações formais, como forma mais rigorosa de compreender os modos próprios de ser do ser-aí.

Pelo posicionamento hermenêutico do questionamento heideggeriano, a clínica se torna uma convocação que orienta tanto o terapeuta quanto o paciente para uma coabitação numa morada em comum, em sua constitutiva e originária facticidade. A condição do pensar e do dizer encontram-se nos interstícios da escuta do apelo de um outro ek-sistente, "acolhendoo como hóspede de uma casa que a nenhum dos dois pertence" (Duarte, 2010, p. 411). A atenção clínica como disposição afetiva ao acolhimento e cuidado, fundada na temporalização ek-stática própria do ser-aí, significa dizer que existe uma possibilidade sempre minha, a morte.

A clínica como situação hermenêutica, logo, orienta o desvelamento que se entremostra em círculos como uma faísca, um vislumbre no jogo fenomenológico radical em 
meio a inautenticidade fáctica do Dasein, que segue o seu curso como destino historial. A forma de captação instantânea e fugaz em meio a inautenticidade se dá pela angústia, enquanto uma tonalidade afetiva fundamental que possibilita a singularização mais própria do ser do ser-aí numa dinâmica que, incessantemente, enseja novos inícios de essencialização e compreensão do ser. O terapeuta, ao desenvolver a ação clínica como preocupação e solicitude - Fürsogen, Barreto (2017) aproxima-se ao que Sena (2012) descreve em sua problematização sobre a fenomenologia como terapêutica: o "discurso formal-indicativo" (p. 68) da vida fáctica tem por tarefa exortar a existência do sono para a vigília, para uma apropriação compreensiva de si mesmo. Sena (2012) descreve que a fenomenologia em sua versão hermenêutica, já edificada em seus primórdios na fase que antecede a Ser e Tempo, não deve ser compreendida como uma teoria filosófica da existência humana, mas tão somente como uma práxis terapêutica da facticidade, cuja tarefa principal não caberia a explicações e esclarecimentos, mas, tão primordialmente e originariamente, à exortação do ser existente, concreto e histórico à sua tarefa de cuidado em seu existir em si e com os outros-nomundo. Para essa exortação, logo, a ação clínica como acolhimento ao outro se dá pela indicação da situação hermenêutica no encontro clínico.

A situação clínica parte, simultaneamente, do ponto de vista fixo e próprio do paciente e do terapeuta. Pelo ponto de vista existencial do paciente, a situação hermenêutica em sua circularidade própria posiciona a visada inicial pelas sedimentações de seus modos próprios de ser. Pela perspectiva de apreensão da facticidade da existência, em suas disposições de ser si-mesmo e ser-com-uns-com-os-outros em sua realidade concreta, novos significados poderão desvelar-se no encontro terapêutico e abrir novos horizontes de sentido, novos caminhos que se produzem ao existir. Assim sendo, o paciente poderá se lançar e projetar a sua vida como cuidado de si, o que significa pôr-se em movimento, a partir de seu modo próprio de ser (Barreto, 2017). Em consonância, pelo ponto de vista do terapeuta, o gesto fenomenológico de abertura, o qual favorece a ambiência necessária do exercício clínico como indicação da situação hermenêutica, só é possível se ele, terapeuta, parte do ponto de vista fixo e próprio da tradição metafísica cientificista sedimentada no campo da Psicologia, especificamente, pela realidade multifacetada do arsenal de teorias e técnicas psicoterapêuticas, para uma outra perspectiva clínica fundada na compreensão existencial do paciente, com base no encontro e no diálogo. Na situação hermenêutica, portanto, que promova a existência como modos de favorecer a vida desperta pela mostração fenomenal da verdade dessa trajetória. 


\section{Considerações Finais}

À guisa de conclusão, é possível indicar que a clínica como situação hermenêutica vai se configurando na medida em que o paciente, do ponto de vista existencial, luta para conseguir sair do habitual, dos comportamentos aprendidos e fixados na busca de novas perspectivas de vida nas quais, cuidando de si, procura reconfigurar, reconstruir a própria vida. Para acompanhá-lo nessa caminhada, o clínico precisa assumir outro ponto de vista, libertando-se das premissas tradicionais, que orientam as diversas escolas psicológicas, e assumir uma perspectiva terapêutica, pautada pelo encontro e diálogo, na intenção de possibilitar que a verdade encontre seu caminho fenomenológico de aparecer, desvelando o sentido singular de cada fenômeno, de modo que sua ação caminhe para outro horizonte de sentido: acompanhar aquele que procura ajuda para cuidar de seu sofrer e possa "se apropriar do que já sabe pré-reflexivamente, tematizando as experiências que vão se desvelando no existir" (Barreto, 2013, p. 39).

\section{Referências}

Barreto, C. L. B. T. (2013). Reflexões para pensar a ação clínica a partir do pensamento de Heidegger: Da ontologia fundamental à questão da técnica. In C. L. B. T. Barreto, H. T. P. Morato, \& M. T. Caldas (Eds.), Prática psicológica na perspectiva fenomenológica existencial (pp. 27-50). Curitiba: Juruá.

Barreto, C. L. B. T. (2017). A ontologia heideggeriana do cuidado e suas ressonâncias na ação clínica. In B. E. B. Cabral, C. L. B. T. Barreto, M. J. Kovács, \& M. L. S. Schmidt (Eds.), Prática psicológica em instituições: Clínica, saúde e educação (pp. 39-49). Curitiba: CRV.

Borges-Duarte, I. (2016). O afecto na análise existencial heideggeriana. Cultura: Revista de História e Teoria das Ideias, 35, 135-150. doi:10.400/cultura.2603

Duarte, A. (2010). Heidegger e a linguagem: O acolhimento do ser como acolhimento do outro. In A. Duarte, Vidas em risco: Crítica do presente em Heidegger, Arendt e Foucault (pp. 381-411). Rio de Janeiro: Forense Universitária.

Gadamer, H. G. (2007). Hermenêutica em retrospectiva: Heidegger em retrospectiva. Petrópolis: Vozes. 
Hebeche, L. (2003). Reabilitando a hermenêutica da facticidade: Sobre "Desmitilogizando Heidegger de John D. Caput. Revista Portuguesa de Filosofia, 59(4), 1309-1320. Recuperado de https://www.jstor.org/stable/40337800?seq=1

Heidegger, M. (1989). Heideggerische definition der hermeneutischen situation (I. BorgesDuarte, Trad.). In M. Heidegger, Phãnomenologische interpretationen zu Aristoteles: Anzeige der hermeneutischen situation (pp. 237-238). Frankfurt: H.U. Lessing. (Obra original publicada em 1922).

Heidegger, M. (1991). O fim da filosofia e a tarefa do pensamento. In M. Heidegger, Conferências e escritos filosóficos (pp. 65-81). São Paulo: Nova Cultural.

Heidegger, M. (2002). Interpretaciones fenomenológicas sobre Aristóteles: Indicación de la situación hermenéutica [Informe Natorp]. Madrid: Trotta. (Obra original publicada em 1922)

Heidegger, M. (2009). Meu caminho na fenomenologia. (A. Falcato, Trad.). Covilhã: Universidade da Beira Interior. Recuperado de http://www.lusosofia.net/textos/heidegger_martin_o_meu_caminho_na_fenomenologi a_.pdf

Heidegger, M. (2010). Phenomenological interpretations with respect to Aristoteles: Indication of the hermeneutical situation (Natorp Bericht). In B. Hopkins, \& J. Drummond (Eds.), The New Yearbook for Phenomenology and Phenomenological Philosophy (pp 144-179). London: Routledge Taylor \& Francis Group.

Heidegger, M. (2011). Interpretações fenomenológicas sobre Aristóteles: Introdução à pesquisa fenomenológica. Petrópolis: Vozes.

Heidegger, M. (2012a). Os problemas fundamentais da fenomenologia. Petrópolis: Vozes.

Heidegger, M. (2012b). Ontologia: Hermenêutica da facticidade. Petrópolis: Vozes.

Heidegger. M. (2015). Ser e Tempo. Petrópolis: Vozes.

Heidegger. M. (2017). Seminários de Zollikon. São Paulo: Escuta.

Peraita, C.S. (2002). Hermenéutica de la vida humana: En torno al informe Natorp de Martin Heidegger. Madrid: Trotta.

Peraita, C. S., \& Santos, J.F. (2009). A vida fáctica em Heidegger: Além da representação. $\begin{array}{llll}\text { Controvérsia, } & 5(2), & \text { 77-86. } & \text { Recuperado }\end{array}$ http://revistas.unisinos.br/index.php/controversia/article/view/6698/3743

Rubenich, A. A. (2014). Hermenêutica da facticidade no jovem Heidegger. Natureza Humana, 16(2), 16-28. Recuperado de http://revistas.dwwe.com.br/index.php/NH/article/view/56 
Sá, A. F. (2008). Da destruição fenomenológica à confrontação: Heidegger e a incompletude da ontologia fundamental. Covilhã: Universidade da Beira Interior. Disponível em: http://www.lusosofia.net/textos/sa_alexandre_destruicao_fenomenologica_confrontac ao_heidegger.pdf

Sena, S. M. M. (2012). Jogue a escada fora: Fenomenologia como terapêutica. Natureza Humana, 14(2), 37-73. Recuperado de http://pepsic.bvsalud.org/pdf/nh/v14n2/a03.pdf Volpi, F. (2013). Heidegger e Aristóteles. São Paulo: Loyola.

Wu, R. (2012, Julho). Hermenêutica enquanto fenomenologia do "como": O "Natorp Bericht” de Heidegger. Comunicação apresentada na II Jornadas Internacionales de Hermenéutica: La hermenéutica en diálogo con las ciencias humanas y sociales: Convergencias, contraposiciones y tensiones. Buenos Aires, Argentina: Proyecto. Recuperado de http://proyectohermeneutica.sociales.uba.ar/wpcontent/uploads/sites/31/2016/12/88.II-Jornadas.pdf

\section{Endereço para correspondência}

\section{Angela Cardoso Andrade}

Rua Visconde de Mauá, 1661, Aldeota, Fortaleza - CE, Brasil. CEP 60125-160

Endereço eletrônico: angelaandrade@ unifor.br

\section{Carmem Lúcia Brito Tavares Barreto}

Rua Astronauta Neil Armstrong, 120 apto 1101, Recife - PE, Brasil. CEP 52060-170

Endereço eletrônico: carmemluciabarreto@hotmail.com

Recebido em: 01/07/2020

Reformulado em: 13/09/2020

Aceito em: 18/09/2020

\section{Notas}

* Psicóloga. Doutora em Saúde Coletiva pela Universidade Federal do Ceará. Pós-doutoranda em Psicologia Clínica pela UNICAP. Professora do Centro de Ciências da Saúde da UNIFOR.

** Doutora em Psicologia pela USP. Pós-doutora em Filosofia pela Universidade de Évora. Professora do PPG em Psicologia Clínica e Coordenadora do LACLIFEP da UNICAP.

${ }^{1}$ Destruição - Destruktion - tem por significação a desconstrução dos conceitos ontológicos tradicionais ao se referir à atitude de confronto e apropriação da tradição, a partir do método fenomenológico, ao reelaborar sistemas de pensamento até então herméticos que visavam a enunciação de um estado de coisas pela mera presença. Heidegger torna possível a revitalização pela radicalidade do pensar e, assim, tornar efetivo os temas 
filosóficos, como coisa pensada, buscando escapar dos temas filosóficos como objetos de erudição (Heidegger, 1991).

${ }^{2} \mathrm{O}$ fundamental da perspectiva fenomenológica heideggeriana é o acesso e apreensão do ser dos entes, tais como eles se mostram por si mesmos.

${ }^{3}$ Heidegger não formula em seu pensamento categorias analíticas que convergem à tradição metafísica de ciência, ou seja, premissas no âmbito teorético-conceituais, com vistas à universalização. Propõe indicativos formais que acenam para pressupostos que possibilitam uma nova ótica de apreensão do ser dos entes.

${ }^{4}$ A visão fenomenológica do Dasein (ser-aí) do existente humano se expressa como compreensão, afetabilidade e linguagem. Existimos desde sempre compreendendo, ou seja, numa atividade de pré-compreensão daquilo que nos toca. Este movimento de apreensão é atravessado por uma determinada disposição ou tonalidade afetiva na qual se mostra pela linguagem.

Este artigo de revista Estudos e Pesquisas em Psicologia é licenciado sob uma Licença Creative Commons Atribuição-Não Comercial 3.0 Não Adaptada. 